\title{
Existence of the Essential Features of the Function Concept in Public Secondary Students' Definitions
}

\author{
Huda Faour \\ Lebanese University
}

\begin{abstract}
This paper aims to explore the existence of the essential features of the function concept in public secondary students' definitions of it across grade-level of the scientific and humanities tracks. A sample of $\mathbf{4 6 5}$ secondary students was chosen from 5 public secondary schools located in Beirut. The findings of the study showed that secondary students in the different grade levels lack a thorough conceptualization of what is a function. For instance, the majority of them failed to give definitions that reflect the essential features of the concept. The relation feature was the most one noticed in students' definitions. Compartmentalization phenomenon was observed where even the students who succeeded to state the uniqueness property, were not truly aware of it and seemed not to consult this property when presented with non-examples of function.
\end{abstract}

Keywords:- The function concept; Definition of function; Compartmentalization phenomenon; The uniqueness property.

\section{INTRODUCTION}

Learning definitions of mathematical concepts is the first step in the learning process of communicating mathematics formally [11]. But they differ from the "everyday language" definitions in terms of creation and use. Mainly, the "everyday language" definitions are extracted definitions - the ones that report usage, while mathematical definitions are stipulated definitions - the ones that create usage [4]. And, as Edwards and Wards [4] stated: "when a term is defined by stipulation, it is to be free from connotation, that is, free from all the associations the term may have acquired in its nontechnical use" (p. 413). For instance, the mathematical term function has nothing to do with the word function used in everyday language.

The function concept is a crucial topic in secondary school, in which students need to develop a robust understanding of it [12]. Concerning the definition of this concept, two essential features have historically evolved and led to the modern formal definition: arbitrariness and uniqueness [8]. Mainly, the uniqueness property is the definitional property of the concept and it states "for every $x$ there is a unique $y$ ". The arbitrary nature refers to both the relation between the sets as well as the sets themselves [7]. In this study, the essential features of the function concept in students' definitions refer to the uniqueness property, the relation, and the sets.

\section{LITERATURE REVIEW}

Many studies have documented students' definitions of the function concept. In some definitions, it was reflected as a dependence relation, yet without referring to the uniqueness property or the domain and range $[5,6,18]$, or as a rule - a relation between sets that assumes some kind of regularity $[16,18]$. Also, definitions that viewed function as an equation that relates inputs and outputs, a graph, or a series of arithmetical calculations were common $[15,16,18,20]$. Defining function in terms of its representations, an equation, or a graph, might be due to their experience with the multiple representations of functions. Especially since the only access to a mathematical concept is through its representations [3].

Studies that addressed students' definitions of the function concept revealed many difficulties in comprehending the essential features of this concept. According to the uniqueness property, three categories have been identified in the literature. In the first category, students who showed no awareness of this property. Such students might tend to accept a circle as a function based on their concept images related to having a complete graph or an equation in $x$ and $y$ without making sense of the relation between the two variables $[15,19]$. Secondly, students who erroneously recalled this property as every $y$ in the range has a unique $x$ in the domain, due to the erroneous rote memorization of the textbook definition [16]. The last category includes students who developed the conception that a function is necessarily a one-to-one correspondence [5]. Such condensing of the uniqueness property might hinder students' understanding of the function concept as a more thorough concept [6]. For example, Piya, a student who tended to use both the vertical line test and the horizontal line test to decide whether a specific graph represents a function, rejected a parabola to be a graph of a function since the horizontal lines crossed the graph twice [10]. Vinner [16] attributed this conception to a distortion of the function definition that resulted from what he called the implicit requirement for symmetry.

While the uniqueness property is stated explicitly, the arbitrary nature of the function concept remains implicit in the definition. Studies revealed that students developed conceptions about the function concept that contradict its 
arbitrary nature. On the one hand, studies showed that students emphasized the regularity of the relation by conceiving a function as a relation that should be governed by a certain law, seeing it as an equation or accepting only "reasonable" graphs to represent functions $[15,16,18]$. On the other hand, even though the arbitrariness of the two sets means that functions do not have to be defined only on numerical sets [7], the definitions given by many students reflected their reliance on sets of numbers $[15,16]$. Some students narrowed it down, even more, to $\mathbb{R}$ - the set of real numbers. For example, some students rejected a function that was defined on a subset of $\mathbb{R}$, in particular, the set of rational numbers, which can be attributed to their experience with functions that were defined almost everywhere in $\mathbb{R}[15]$.

Studies revealed that students' inability to give correct definitions of the function concept continued to the university level. For instance, Elia and Spyrou [5] reported that the majority of university students failed to give satisfying definitions of function, with only $8 \%$ of them could provide definitions that stated the essential features of the concept. Mainly, studies that addressed students' definitions, at both secondary and university level, tended to categorize them into non-overlapping categories and not to scrutinize the presence of each of the essential features of the concept $[5,6,9,15,16,18]$. However, the present study was concerned with examining the existence of these features in students' definitions and not just categorizing them. Since even students who could give correct definitions seemed not to use them in identifying the concept [16]. This study was interested in testing whether the students who could state the uniqueness property correctly were really aware of it by examining their performance on identifying non-examples of functions. Moreover, the previous studies addressed this topic at specific stages of secondary and university levels. In this study, all grade levels of the different tracks, whether scientific or humanities, of secondary school, were considered to give a broader picture in this context and to test if the situation improves over the school years. One study was found to address secondary students' definitions of the function concept across all grade levels, yet, it only categorized their definitions in terms of correctness without discussing how these definitions reflected each feature of the concept [14].

Hence, the main aim of this study was to investigate the essential features of the function concept in public secondary students' definitions. For this purpose, this paper was sought to provide answers to two research questions:

$>$ How do public secondary students' definitions of the function concept reflect the essential features of it throughout secondary school years?

$>$ How aware are the students who stated the definitional property of the function concept of this property?

\section{METHOD}

\section{A. Students'sample}

There are 18 public secondary schools located in Beirut. However, the eight schools where French is the only language of instruction were excluded. And, five schools were chosen out of the ten remaining ones. A sample of 465 secondary students was selected using a multistage stratified cluster sampling technique.

In Lebanon, secondary education consists of grades 10,11 , and 12. In grade 11, there are two sections: Sciences (S) and Humanities $(\mathrm{H})$. And, at grade 12, there are four sections: General Sciences (GS), Life Sciences (LS), Sociology and Economics (SE), and Literature and Humanities (LH). The distribution of students according to these grade levels and streams was as follows: 125 students in grade 10, 153 in grade 11 (85 in $11(\mathrm{~S})$ and 68 in $11(\mathrm{H})$ ), 187 in grade 12 (26 in 12(GS), 69 in $12(\mathrm{LS}), 83$ in $12(\mathrm{SE})$ and 9 in $12(\mathrm{LH})$ ).

\section{B. Instrument and data collection}

Data was collected in the academic year 2017-2018, using a test consists of three parts; only the first two are of concern to this study. In the first part, students were asked the question, "In your opinion, what is a function?". This open-ended question was used to inform about students' definitions of this concept.

In the second part, students were presented with the concept identification (CI) test. It is a 30 -item multiplechoice test, measuring student's ability to recognize exemplars and non-exemplars of the function concept. It was structured based on two criteria: representation mode (algebraic, graphical, tabular) and relation type (constant, linear, quadratic, other). However, this test is part of another work. And in this study, it was used only to inform about students' awareness of the uniqueness property. Cronbach's alpha coefficient of 0.848 indicated a good internal consistency of the test. Furthermore, content validity was assured by three math teachers: two doctoral candidates and a master's degree holder in math education.

\section{Data analysis}

$>$ The Essential Features of the Function Concept in Students' Definitions

Since the purpose of the study was to spot the essential features of the function concept in students' definitions, three categories were identified deductively based on the existence of the determining features of the concept: the uniqueness property, the relation, and the sets (domain and range). Student's response can be assigned to more than one category. If the response did not show a trace of any of these three categories it was coded other.

Moreover, the Chi-squared test of independence, at a p-value level of 0.05 , was used to test for statistically significant differences across grade-level. 


\section{Students' Awareness of the Uniqueness Property}

Seven items of the concept identification test were non-examples of the function concept ( 2 in the algebraic mode, 2 in the graphical mode, and 3 in the tabular mode). Among the students who stated the uniqueness property correctly in their definitions, only the student who answered correctly to all these items was assumed to be and coded as aware of the uniqueness property. Otherwise, the student was coded as unaware of it.

\section{RESULTS}

A. The Essential Features of the Function Concept in Students' Definitions

The essential features of the function concept were traced in $198(43 \%)$ of students' responses, yet $267(57 \%)$ responses were coded other.

\section{Responses that reflected the essential features}

Table 1 shows the number of responses related to each of the three categories regarding the essential features across the different grade levels, as well as the percentages within each grade-level. The total number of responses in the three categories did not sum up to 198 responses, the ones where the essential features were traced since student's response can be assigned to more than one category.

\begin{tabular}{|c|c|c|c|}
\hline \multirow{2}{*}{ Grade level } & \multicolumn{3}{|c|}{$\begin{array}{c}\text { Responses in each Category } \\
\text { Count (\%) }\end{array}$} \\
\cline { 2 - 4 } & Uniqueness property & Relation & Domain and range \\
\hline Gr. 10 & $28(22)$ & $36(29)$ & $1(6)$ \\
\hline Gr.11(S) & $12(14)$ & $41(48)$ & $8(12)$ \\
\hline Gr. 11(H) & $9(13)$ & $20(29)$ & $2(8)$ \\
\hline Gr. 12(GS) & $4(15)$ & $15(58)$ & $1(1)$ \\
\hline Gr. 12(LS) & $3(4)$ & $29(42)$ & $0(0)$ \\
\hline Gr. 12(SE) & $1(1)$ & $20(24)$ & $0(0)$ \\
\hline Gr. 12(LH) & $0(0)$ & $2(22)$ & $19(4)$ \\
\hline Total & $57(12)$ & $163(35)$ & \\
\hline
\end{tabular}

Table 1:- Distribution of Responses by Grade-level and Essential Feature Category

As shown in Table 1, responses that reflected some kind of relation were the most prevalent, with $35 \%$ of secondary students' responses reported in this category. The presence of relation statistically significantly increased in students' definitions across grade-level in both the GS $\left(\chi^{2}(2, N=236)=12.33, p=0.002\right)$ and LS streams $\left(\chi^{2}(2, N\right.$ $=279)=8.75, p=0.013)$ of the sciences track. For instance, $29 \%$ of $10^{\text {th }}$ graders reported in this category, in comparison to $48 \%$ of $11^{\text {th }}$ graders in the scientific section and $58 \%$ and $42 \%$ of the $12^{\text {th }}$ graders in the GS and LS sections, respectively. However, the presence of relation did not increase across grade-level of the humanities stream.

Concerning the uniqueness property, only $12 \%$ of secondary students referred to it in one way or another. Trace of this property was noted in less than a quarter of the $10^{\text {th }}$ graders' responses, more precisely $22 \%$ of them. But, the presence of it diminished across grade-level of both tracks.

\begin{tabular}{|c|c|c|c|c|c|c|c|c|c|}
\hline \multirow[t]{2}{*}{$\begin{array}{l}\text { Grade } \\
\text { level }\end{array}$} & \multicolumn{9}{|c|}{$\begin{array}{c}\text { Responses in each Sub-category } \\
\text { Count }(\%)\end{array}$} \\
\hline & $\begin{array}{c}\text { Variables } \\
\text { only }\end{array}$ & Calculation & Machine & Variation & Dependence & Rule & Mapping & Relation & $\begin{array}{l}\text { Mapping } \\
\text { \& relation }\end{array}$ \\
\hline Gr.11(S) & $11(13)$ & $1(1)$ & $0(0)$ & $15(18)$ & $0(0)$ & $0(0)$ & $0(0)$ & $14(17)$ & $0(0)$ \\
\hline Gr. 11(H) & $7(10)$ & $3(4)$ & $0(0)$ & $0(0)$ & $0(0)$ & $0(0)$ & $0(0)$ & $10(15)$ & $0(0)$ \\
\hline $\begin{array}{c}\text { Gr. } \\
12(\mathrm{GS})\end{array}$ & $3(12)$ & $1(4)$ & $2(8)$ & $2(8)$ & $0(0)$ & $0(0)$ & $0(0)$ & $7(27)$ & $0(0)$ \\
\hline $\begin{array}{c}\text { Gr. } \\
\text { 12(LS) }\end{array}$ & $9(13)$ & $3(4)$ & $1(1)$ & $10(15)$ & $2(3)$ & $0(0)$ & $0(0)$ & $4(6)$ & $0(0)$ \\
\hline $\begin{array}{c}\text { Gr. } \\
12(\mathrm{SE})\end{array}$ & $6(7)$ & $7(8)$ & $0(0)$ & $5(6)$ & $0(0)$ & $1(1)$ & $0(0)$ & $1(1)$ & $0(0)$ \\
\hline $\begin{array}{c}\text { Gr. } \\
12(\mathrm{LH})\end{array}$ & $1(11)$ & $0(0)$ & $0(0)$ & $1(11)$ & $0(0)$ & $0(0)$ & $0(0)$ & $0(0)$ & $0(0)$ \\
\hline
\end{tabular}

Table 2:- Distribution of Responses by Grade-level and Relation Sub-category 
Finally, the less emphasized feature in their responses was the sets (domain and range) where only $4 \%$ of secondary students referred to this feature in their definitions.

Moreover, for each of the relation and uniqueness property categories, sub-categories were determined such that within each category, the response can be assigned to a single sub-category.

\section{- Sub-categories related to the relation feature}

Each response in the relation category was assigned to only one of the nine sub-categories identified in students' definitions. Table 2 shows how the responses that reflected the presence of some kind of relation were distributed across the different grade levels. It is important to note that the relation category included the responses where some kind of a relation between the two variables was noted, even though implicitly by indicating the variables only. In contrast, the responses classified in the sub-category relation were only the ones where the term relation was stated explicitly. Responses in the relation category were mainly clustered in three sub-categories: variables only, relation, and variation.

For instance, $11 \%$ of secondary students' responses referred to the two variables $x$ and $y$ without a clear indication of a relation (about $31 \%$ of the responses in this category). It seems that a fairly comparable amount, around $10 \%$ of students in each grade level were likely to refer to the variables only. However, the term "relation" was explicitly stated by $9 \%$ of the students, which constituted about a quarter of the responses in this category. The use of the term "relation" seemed to increase across grade-level in the scientific track, in particular in the GS stream. Whereas the term relation was spotted in about $6 \%$ of $10^{\text {th }}$ graders' responses, $17 \%$ and $27 \%$ of the students in the scientific section of grade 11 and grade 12(GS) found to mention it, respectively. Moreover, about half of the responses that referred to a variation between $x$ and $y$ were given by $11^{\text {th }}$ graders in the scientific section, while the other half was distributed among the different sections of grade 12 .

Below are presented some examples of students' definitions, in their own words, which classified in the relation category. The ordered pair, at the end of the example, represents (grade-level; sub-category):

$\checkmark$ Function is a relation between $\mathrm{x}$ and y (Gr. 11(S); relation);

$\checkmark$ The function is the variation of $\mathrm{y}$ with respect to $\mathrm{x}(\mathrm{Gr}$. 12(LS); variation);

$\checkmark$ The function is about $\mathrm{x}$ and $\mathrm{y}$ (Gr. 10; variables only);

$\checkmark$ Mapping from $x$ to y (Gr. 10; mapping).

\section{- Sub-categories related to the uniqueness property}

Four sub-categories were identified in students' definitions where the uniqueness property sensed. Table 3 shows how students' definitions reflected this property across the different grade levels.

\begin{tabular}{|c|c|c|c|c|}
\hline \multirow{2}{*}{ Grade level } & \multicolumn{5}{|c|}{ Responses in each Sub-category } \\
Count $(\%)$
\end{tabular}

*note that VLT: vertical line test, UQ: universal quantification, UP: uniqueness property.

Table 3:- Distribution of Responses by Grade-level and Uniqueness Property Sub-category*

Only $12 \%$ of secondary students' definitions found to indicate the uniqueness property. Table 3 reports that the majority of students in this category succeeded in stating this property correctly, yet these 41 responses constituted only $9 \%$ of their responses in general. These responses were clustered in the grade levels of the scientific track, with no increase noted across grade-level. Moreover, an indirect reference to the uniqueness property by indicating universal quantification, i.e., stating "for every $x$ " without referring to the uniqueness of $y$, was found in students' responses but with inconsiderable percentages. Also, very few responses, reported only in grade 10, implicitly referred to this property by indicating the use of the vertical line test. And, only 4 students stated it incorrectly.
In what follows some of the students' definitions, that reflected the uniqueness property in one way or another, are presented, the ordered pair represents (grade-level; subcategory):

$\checkmark$ The function is every $\mathrm{x}$ have y (Gr. 10; referring to universal quantification);

$\checkmark$ For every $\mathrm{x}$ one y (Gr. 11(S); correctly stating the uniqueness property);

$\checkmark$ Function is $\mathrm{y}$ in terms of $\mathrm{x}$, for every $\mathrm{y}$ there is one $\mathrm{x}$ (Gr. 11(S); incorrectly stating the uniqueness property);

$\checkmark$ If I do straight line and passing through many points is not function (Gr. 10; referring to the vertical line test). 
As mentioned earlier, some responses might assign to more than one category. The following two definitions are examples of such responses. For instance, they were found to reflect two of the essential features of the function concept: relation and uniqueness property. The ordered pair, at the end of students' definitions, represents (gradelevel; sub-category of relation, sub-category of uniqueness property):

$\checkmark$ Function is the relation between $\mathrm{x}$ and $\mathrm{y}$, and for every $\mathrm{y}$ has one value of $\mathrm{x}(\mathrm{Gr} .11(\mathrm{~S})$; relation, incorrectly stating the uniqueness property);

$\checkmark$ A function is a machine that gives for every input $\mathrm{x} 1$ and only one output y (Gr. 12(GS); machine, correctly stating the uniqueness property).

\section{$>$ Other responses}

Among the responses coded other, three categories were distinguished. In the first one, 106 responses were somehow related to the function concept, referring to representation and/or property of it, yet not reflecting any of its features. In the second category, 57 responses were classified as irrelevant. And finally, 104 responses were coded no answer where students did not give any answer.

Below are presented examples of students' responses which coded either related to functions or irrelevant, the ordered pair represents (grade-level; category):

- The function is an equation in terms of $\mathrm{x}$ (Gr. 12(LS); related to functions);

- Function is an equation given to us and it can be translated into a table or graph (Gr. 12(SE); related to functions);

- A function is a sketch that represents a certain shape and a set of points (Gr. 12(LS); related to functions);

- The study of lines or graphs, either algebraically or graphically (Gr. 11(H); related to functions);

- A function can be: rational - irrational - polynomial (Gr. 10; related to functions);

- We didn't take a definition of function (Gr. 12(SE); irrelevant);

- I know the lesson but not its definition (Gr. 12(SE); irrelevant);

- Something we don't use in our real life (Gr. 12(LH); irrelevant).

As a final remark on students' definitions, even though this study was concerned mainly in spotting the essential features of the function concept, about $34 \%$ of secondary students referred to its representations either in responses where these features were noted or not.

\section{B. Students' Awareness of the Uniqueness Property}

Only $9 \%$ of secondary students stated the uniqueness property correctly in their definitions. Among these students, only 2 of them might be assumed to be aware of it since they rejected all the seven non-examples, given in the CI test, as functions. This inconsistent behavior in stating the uniqueness property correctly and not consulting it in identifying non-examples of functions provides evidence of the existence of the compartmentalization phenomenon across all grade levels of secondary school, see Table 4.

\begin{tabular}{|c|c|c|c|c|c|c|}
\hline & \multicolumn{5}{|c|}{ Grade level } & \multirow{3}{*}{$\begin{array}{l}\text { Total } \\
(N=41)\end{array}$} \\
\hline & \multirow{2}{*}{$\begin{array}{c}\text { Gr } 10 \\
(N=19)\end{array}$} & \multicolumn{2}{|c|}{ Gr 11} & \multicolumn{2}{|c|}{ Gr 12} & \\
\hline & & $\begin{array}{c}S \\
(N=8)\end{array}$ & $\begin{array}{c}H \\
(N=8)\end{array}$ & $\begin{array}{c}G S \\
(N=4)\end{array}$ & $\begin{array}{c}L S \\
(N=2)\end{array}$ & \\
\hline $\begin{array}{l}\text { Number } \\
\text { of cases }\end{array}$ & 17 & 8 & 8 & 4 & 2 & 39 \\
\hline$\%$ & 89 & 100 & 100 & 100 & 100 & 95 \\
\hline
\end{tabular}

*These 41 students were the only secondary students who correctly stated the uniqueness property.

Table 4:- Distribution of Cases Reflecting

Compartmentalization by Grade-level*

The 39 students, reported in Table 4, were considered unaware of the uniqueness property since they were found to answer incorrectly to one or more of the seven items of the CI test representing non-examples of function. Table 5 shows the distribution of these incorrect answers to the seven non-examples, either by accepting a non-example as a function or answering by $I$ do not know. In both cases, students did not make use of the property they stated. And, either they were just rote memorizing this property, or they were not aware enough of it, so it kept inactivated.

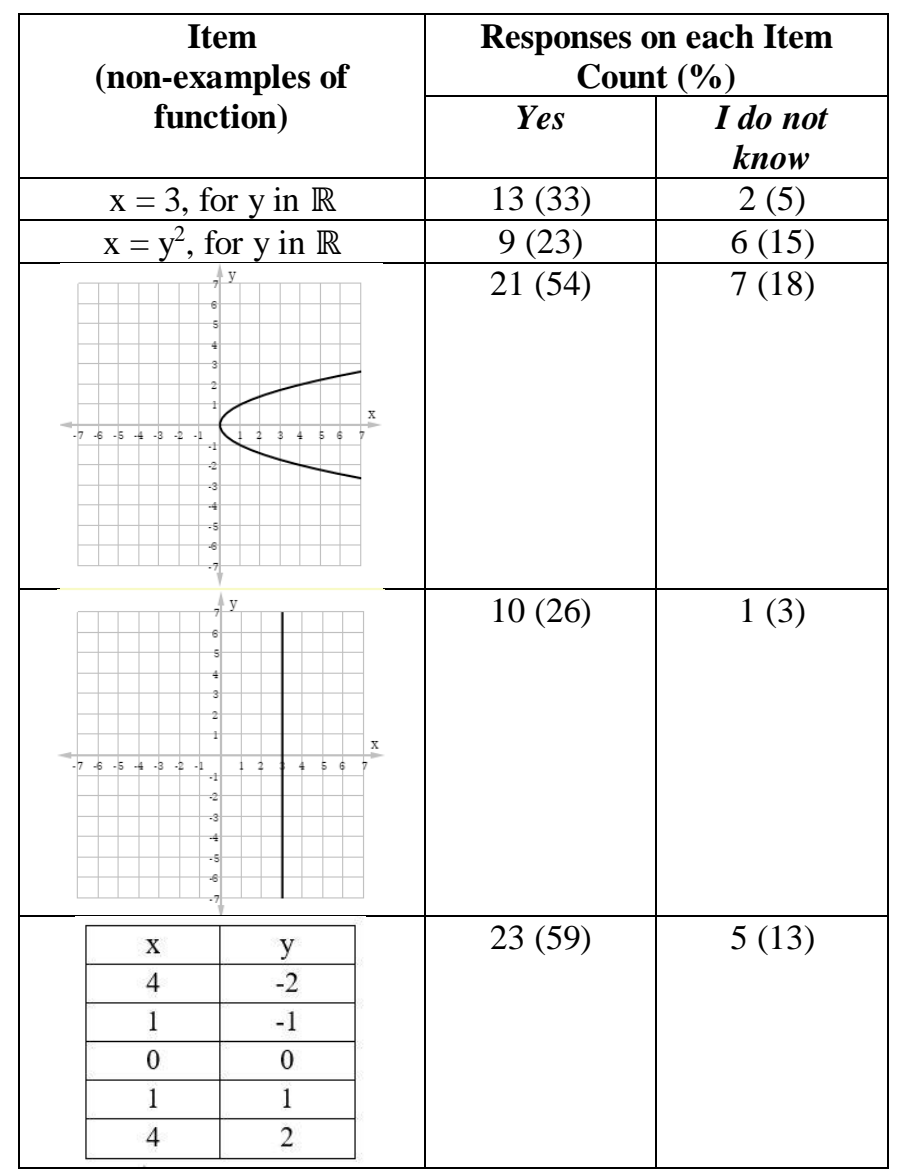




\begin{tabular}{|c|c|c|c|}
\hline$x$ & $\mathrm{y}$ & \multirow[t]{6}{*}{$11(28)$} & \multirow[t]{6}{*}{$5(13)$} \\
\hline 3 & -2 & & \\
\hline 3 & -1 & & \\
\hline 3 & 0 & & \\
\hline 3 & 1 & & \\
\hline 3 & 2 & & \\
\hline $\mathrm{x}$ & $\mathrm{y}$ & \multirow[t]{6}{*}{19 (49) } & \multirow[t]{6}{*}{$5(13)$} \\
\hline $\mathrm{S}$ & Sara & & \\
\hline $\mathrm{H}$ & Huda & & \\
\hline $\mathrm{C}$ & Celia & & \\
\hline $\mathrm{Z}$ & Zeina & & \\
\hline $\mathrm{H}$ & Hala & & \\
\hline
\end{tabular}

*Responses in this table belong to the 39 students who stated the uniqueness property correctly but were coded unaware of it.

Table 5:- Responses that Reflected Students' Unawareness of the Uniqueness Property*

\section{DISCUSSION}

The primary outcome of this study was that secondary students at all grade levels of both tracks still do not grasp the essence of the function concept, where the majority of their definitions did not reflect the essential features of the function concept. And, even after three years of experience with functions in secondary school, students could not develop a profound conceptualization of what is a function. This finding was consistent with many studies that reported students' inability to give satisfying definitions $[5,6,16$, 18, 20], and agrees with Akkoç and Tall [1] who stated that "most of the students do not focus on the essential function properties" (p. 7). Such results might be attributed to the lack of opportunities provided to secondary students to be engaged with the essential features of the function concept. In the context of the official Lebanese curriculum, this concept is defined formally in the first secondary (grade 10) textbook, and definitional practices seemed to be absent in all secondary mathematics textbooks.

Besides, secondary students in this study showed no awareness of the determining property of function, where even the ones who stated the uniqueness property correctly failed to reject non-examples of function. And, it seemed that they did not consult this property but their concept images of function. This outcome seems to be in line with previous work, for which many studies have reported that students did not use the definition for identifying the concept [5, 6, 20]; and this was the case even for the students who could give correct definitions [16, 17]. The root of such behavior can be attributed to treating and miscategorizing mathematical definitions as everyday language definitions. For example, as Edwards and Ward [4] stated, "[h]aving been repeatedly shown instances of a chair, one does not need a definition in order to build or sit in a chair" (p. 416). But mathematical concepts should not be defined in that way, i.e., by extracting the definition from its instances. The failure to view and use mathematical definitions as stipulated ones might hinder students' understanding of the concept itself. Hence, the definition remains inactive. And, instead of using it to sort instances and non-instances of the function concept, contrariwise, they construct their definitions based on the conceptions that developed through experiencing many instances of it [17].

Moreover, compartmentalization cases were reported in all grade levels of secondary school and did not decrease in the higher and more mathematically oriented ones. This outcome was inconsistent with the results found by Vinner and Dreyfus [18], where they stated that "there are fewer cases of compartmentalization by students at higher level courses ... [and] that compartmentalization is quite rare in mathematically oriented students" (p. 365). However, their study was conducted at the university level and not the secondary school one.

To conclude, secondary students, irrespective of grade-level or track, seemed to have a fragile grasp of the core concept of function. And, to help them acquire a deep awareness of the essential features of it, one cannot rely on their experience with different types and representations of functions. In fact, a mathematical definition should be taught, understood and activated, and not only presented to students or memorized by them. For that reason, definitional activities should not be ignored in classroom practice. Baldinger, Campbell, and Graif [2] emphasized the importance of practices such as constructing a definition and engaging students with whole-class discussions. In particular, Nilsen [13] stated that "by omitting explicit discussions related to the definition of the function concept, essential properties of functions might not be clear to the students" (p. 164).

\section{REFERENCES}

[1]. Akkoç, H., \& Tall, D. (2005). A mismatch between curriculum design and student learning: The case of the function concept. In Proceedings of the sixth British Congress of Mathematics Education (Vol. 25, pp. 1-8). University of Warwick.

[2]. Baldinger, E. E., Campbell, M. P., \& Graif, F. (2020). Sorting out definitions. The Mathematics Teacher, 113(3), 209-215.

[3]. Duval, R. (2006). A cognitive analysis of problems of comprehension in a learning of mathematics. Educational Studies in Mathematics, 61(1), 103-131.

[4]. Edwards, B. S., \& Ward, M. B. (2004). Surprises from mathematics education research: Student (mis)use of mathematical definitions. The American Mathematical Monthly, 111(5), 411-424.

[5]. Elia, I., \& Spyrou, P. (2006). How students conceive function: A triarchic conceptual-semiotic model of the understanding of a complex concept. The Mathematics Enthusiast, 3(2), 256-272. 
[6]. Evangelidou, A., Spyrou, P., Elia, I., \& Gagatsis, A. (2004). University students' conceptions of function. In M. J. Høines \& A. B. Fuglestad (Eds.), Proceedings of the 28th Conference of the International Group for the Psychology of Mathematics Education (Vol. 2, pp. 351-358). Bergen, Norway.

[7]. Even, R. (1993). Subject-Matter knowledge and pedagogical content knowledge: Prospective secondary teachers and the function concept. Journal for Research in Mathematics Education, 24(2), 94116.

[8]. Freudenthal, H. (2002). Didactical phenomenology of mathematical structures. Kluwer Academic Publishers.

[9]. Gagatsis, A., Elia, I., Panaoura, A., Gravvani, K., \& Spyrou, P. (2006). An empirical four-dimensional model for the understanding of function. In $\mathrm{J}$. Novotná, H. Moraová, M. Krátká, \& N. Stehlíková (Eds.), Proceedings 30th Conference of the International Group for the Psychology of Mathematics Education (Vol. 3, pp. 137-144). Prague: PME.

[10]. Heingraj, C., \& Shield, M. (2002). One student's understanding of the concept of function. In $\mathrm{B}$. Barton, K. C. Irwin, M. Pfannkuch, \& M. O. J. Thomas (Eds.), Proceedings of the 25th annual conference of the Mathematics Education Research Group of Australasia (pp. 326-333). Sydney: MERGA.

[11]. Jamison, R. E. (2000). Learning the language of mathematics. Language and Learning Across the Disciplines, 4(1), 45-54.

[12]. Lloyd, G., Beckmann, S., Zbiek, R. M., \& Cooney, T. (2010). Developing essential understanding of functions for teaching mathematics in grades 9-12. National Council of Teachers of Mathematics.

[13]. Nilsen, H. K. (2013). Learning and teaching functions and the transition from lower secondary to upper secondary school (Doctoral dissertation). University of Agder.

[14]. Panaoura, A., Michael-Chrysanthou, P., \& Philippou, A. (2015). Teaching the concept of function: Definition and problem solving. In K. Krainer \& N. Vondrová (Eds.), CERME 9 - Ninth Congress of the European Society for Research in Mathematics Education (pp. 440-445). Prague, Czech Republic: Charles University in Prague, Faculty of Education and ERME.

[15]. Tall, D., \& Bakar, M. N. (1992). Students' mental prototypes for functions and graphs. International Journal of Mathematical Education in Science and Technology, 23(1), 39-50.

[16]. Vinner, S. (1983). Concept definition, concept image and the notion of function. International Journal of Mathematical Education in Science and Technology, 14(3), 293-305.

[17]. Vinner, S. (1991). The role of definitions in the teaching and learning of mathematics. In D. Tall (Ed.), Advanced mathematical thinking (pp. 65-81). Dordrecht: Springer Netherlands.
[18]. Vinner, S., \& Dreyfus, T. (1989). Images and definitions for the concept of function. Journal for Research in Mathematics Education, 20(4), 356-366.

[19]. Vrabel, A. R. (2014). Function conceptions of AP calculus students (Doctoral Dissertation). University of Pittsburgh.

[20]. Walde, G. S. (2017). Difficulties of concept of function: The case of general secondary school students of Ethiopia. International Journal of Scientific \& Engineering Research, 8(4), 1-10. 